\title{
Chapter 1 \\ Inclusion or Exclusion: UK Education \\ Policy and Roma Pupils
}

\author{
Carol Rogers
}

\begin{abstract}
Education is widely recognised as a key factor in improving social mobility and improving life chances. Therefore, this is fundamental to UK education policy which aims to improve outcomes for all children, particularly those from disadvantaged backgrounds. As a result of expansion of the European Union over the past decade, there has been an increase in the number of Central and Eastern European Roma families settling the United Kingdom. Together with indigenous Gypsies and Travellers, Roma families remain some of the most marginalised and disadvantaged families in the UK, with Gypsy and Roma children having the poorest educational outcomes of all pupil groups. An inclusive educational philosophy underpins the UK educational system, however, there is a tension between current austerity measures and outcome driven education policy and the principles of inclusive practice. Whilst there are examples of good practice and inclusive educational experiences for Roma children, some barriers and exclusions are also evident.
\end{abstract}

Keywords Roma $\cdot$ Education policy $\cdot$ Inclusion $\cdot$ Inclusive education $\cdot$ UK

\section{Introduction}

This chapter will discuss the educational experiences of Roma children in the United Kingdom (UK) considering if they have inclusive learning opportunities or if, as in many other areas of their lives, they face exclusion and disadvantage. The chapter begins by clarifying the complexities of identifying who Gypsies, Roma and Travellers are, followed by a brief outline of the current political position influencing education and Roma migration and settlement in the UK. The discussion then focuses on the interwoven nature of the educational landscape and the tensions between policy enactment and educational practice as: 'Education means different

C. Rogers $(凹)$

School of Human and Social Sciences, Buckinghamshire New University, High Wycombe, UK e-mail: Carol.rogers@bucks.ac.uk 
things to different people according to the context in which they experience it' (Marshall 2018, p. 1). The quote highlights the complexities of education recognising that its aims, purpose and context will vary according to the value that both individuals and society place on it. From a political perspective education is the key to breaking the cycle of intergenerational disadvantage, improving social mobility and the economic growth of the country. Resulting in an outcome driven policy focus. However, for individuals, the value of education and ultimately the outcomes may be determined by the nature of the experience, whether this is inclusive or discriminatory and exclusive. Finally, the chapter will consider the position and experiences of Roma children exploring educational outcomes and areas of good practice.

\section{Defining Gypsies, Roma and Travellers}

Gypsy, Roma and Traveller (GRT) are often used as generic terms to identify members of ethnic groups who are or have been traditionally nomadic. Defining this terminology to identify individual groups and communities is however relatively complex. Across Europe the term 'Gypsy' is often considered racist and offensive, whereas current cultural and policy usage in the UK, 'Gypsy' is the preferred terminology when referring to members of the English Romany community. Whilst 'Traveller' is used both to refer to ethnic minority groups such as Irish and Scottish Travellers and as a generic term to encompass all other groups of nomadic people, or those of nomadic heritage. The use of the word Traveller is increasingly accepted as a politically inclusive term which permits all nomadic people, whatever their ethnic origins, to acknowledge some form of collective identity whilst recognising the structural constraints and common experience of prejudice and racism encountered by all currently nomadic people as well as those who are 'ethnically' Gypsies or Travellers albeit living in housing. Across Europe "Roma" is used as a broad term to include all groups with nomadic histories, (Women's and Equalities Committee 2019). However, in UK policy documents Roma are classified as migrant populations from Europe who share a cultural/linguistic heritage with English (Romany/Romanichal) Gypsies but who, as relatively recent migrants, are perceived of as 'other' than Gypsies and Irish/Scottish Travellers who have a history in mainland Britain of many hundreds of years. English, Welsh and Scottish Gypsy/ Travellers and Irish Travellers are recognised in law as ethnic groups under the Equality Act 2010 and Roma protected by their ethnicity and national identity (Council of Europe 2012; Cromarty 2018; H.M Government Equality Act 2010; Mirga-Kruszelnicka 2017).

UK education policy uses Gypsy/Roma to identify Gypsy and Roma pupils and separate ascription for Irish Travellers. 


\section{The UK in Context}

As this chapter is written the UK is undergoing an unprecedented period of political and economic change following the decision to leave the European Union (EU) in the 2016 referendum (Brexit). The country has a diverse and increasing population which is currently estimated in excess of 66 million people (Office of National Statistics 2018). It is the rapid population growth attributed to increased migration following the right to freedom of movement across the EU that has in part influenced the decision to leave the EU (Wadsworth et al. 2016).

Throughout history people have traversed the world and migrated across continents to trade, avoid persecution and improve their life chances. In the UK, early evidence of migration is attributed to increased trading power in the sixteenth century, with small numbers of European, African, Asian people entering the country (Migration Watch 2018). Although their origins are unclear, it is during this period that Romani Gypsies are first recorded and given the similarities between Romany and Indic Hindi and Sanskrit languages, it is widely accepted that they were nomadic travellers of Indic heritage. The arrival of nomadic people continued into the seventeenth century with an influx of Irish Travellers, who together with Romani Gypsies are now recognised as the indigenous Gypsy and Traveller population (Okely 1983; Bancroft 2005).

Migrant numbers remained relatively small until the twentieth century when successive governments sought to improve the economy by increasing the working population, most notably following the Second World War and when the UK joined the European Union (EU) in 1973 (Migration Watch 2018). However, the more recent expansion of the EU in 2004 and 2007 to include Central and Eastern European countries of Bulgaria, Romania, Poland, Hungary, Slovakia and the Czech Republic resulted in a significant increase in migration to the UK (Morris 2016). Following this expansion, the right to freedom of movement provided many Roma people, amongst others, with the opportunity to move to the UK and other western European countries, aiming to improve their life chances (James 2017; Morris 2016). As a result, net migration from EU countries has continued to increase, trebling between 1995 and 2015 from 0.9 million to 3.3 million (Office of National Statistics 2018; Wadsworth et al. 2016). This unprecedented increase led to moral panic, with influential media and political campaigns capitalising on migration as a key issue in the referendum. Much of the media focus was directed at Roma migrants with overwhelmingly negative reports suggesting that they were 'benefit tourists' and criminals (Naydenova and Butler 2014; James 2017). In contrast to this, migrating Roma families cite employment and improved life chances for their children as their motivation for resettlement (Ryder et al. 2014). Nonetheless, it is against the backdrop of racist discrimination, usually targeted at the indigenous Gypsy and Traveller population, that Roma migrants in the UK also find themselves: having left their home countries to avoid prejudice and disadvantage only to find the same, albeit perhaps to a lesser extent in the UK (Morris 2016). 
Although migration has been a key focus of Brexit, an increase in social disadvantage resulting from austerity measures and driven by the neoliberal politics of post-2010 coalition and conservative governments, has also been influential (Warwick-Booth 2019). Neoliberalism favours marketisation, competition and privatisation. Whilst this ideology aims to improve the economy and reduce inequality through competitive market forces, the social divide is increasing: the rich become richer and the poor poorer (Davidson 2013; Moss 2014; Marshall 2018). This became evident in a decade of austerity which has seen a significant increase in social disadvantage, with three in 10 children now living in poverty and little improvement in intergenerational ethnic minorities experiences of poverty and deprivation. Gypsies, Roma and Travellers are particularly disadvantaged, having the poorest life chances of any ethnic group in the UK (Diacon et al. 2007). Consequently, they face significant disadvantage across the four key social determinants of employment, education, housing and health: experiencing high levels of homelessness or poor housing; barriers to accessing healthcare leading to poorer health outcomes; and the lowest educational attainment levels (Morris 2016; Women's and Equalities Committee 2019).

For some time, education has been recognised as a key driver for improving economic growth and social mobility. As a result, of increasing poverty and social disadvantage not all children have positive early childhood experiences. Hence current education policy has been developed with the aim of providing equal and inclusive education opportunities, as the next sections of the chapter discuss.

\section{The Educational Landscape}

Although the focus of this chapter is on UK education policy, it is important to note that there is not a unified approach to education policy across the four nations of England, Scotland, Wales and Northern Ireland. Although similar, there is not space in the chapter to fully discuss the education policies, frameworks and variations of each nation, so as the largest Roma communities are located in England the focus of this discussion will be the education policy for England (Brown et al. 2013, 2014).

As neoliberalism underpins the political landscape, it is not surprising that it also shapes education policy, shifting the focus of education from a pedagogic approach to one focused on future economic outcomes as stated below:

Education is the engine of our economy, it is the foundation of our culture, and it's an essential preparation for adult life. Delivering on our commitment to social justice requires us to place these 3 objectives at the heart of our education system (Gibb 2015; DfE 2013).

Accordingly, current policy sees education as a tool for economic growth with children viewed as 'future citizens' essential to the economic prosperity and social mobility of the country (Peckham 2017; Marshall 2018). Although education is recognised as the key to social mobility, one of the main challenges with the present 
education system is closing the attainment gap: the gap between the achievements of pupils from different social backgrounds. It is against this backdrop of an increasingly socially and geographically divided country driven by austerity that hinders the progress of closing the attainment gap leaving some children, most notably Gypsy, Roma and Traveller children, struggling to improve their life chances (OFSTED 2014; Cromarty 2018). Currently the national attainment gap at the end of secondary school between disadvantaged pupils and their more affluent peers is 19.3 months (Andrew et al. 2017), increasing to over 2 years for GRT children (Hutchinson et al. 2018). This is illustrated by the national achievement data for 2016, nationally $57 \%$ of pupils attained the expected qualifications of 5 GCSEs (or equivalents) at grades A* to C, including English and Maths. The figure for pupils identifying as Gypsy/ Roma was 9\% (Cromarty 2018). Moreover, it is widely recognised by both researchers and policymakers that the gap between children from different social backgrounds is well established by the age of five. For example, children aged five with poor vocabulary are more than twice as likely to be unemployed at the age of 34 (Andrew et al. 2017).

Recognising how crucial the first 5 years of life are in determining later life chances has resulted in education being the catalyst for improvement. Consequently, the UK's education policy has an 'earlier the better' approach to children's education. Unlike most European countries where formal schooling begins at 6 or 7 years of age, in the UK compulsory schooling starts at 5 years of age, although most children begin formal schooling between the ages of four and five and will have experience of nursery or pre-school from 2 or 3 years of age (McDowall-Clark 2017; Peckham 2017). Underpinning this early start policy are the independent reviews of Field (2010), Marmot (2010) and Allen (2011) who collectively emphasised the need for early intervention to improve individual life chances and break intergenerational cycles of disadvantage. As the importance of the early years became evident, early years' provision has been formalised and influential in reducing early disadvantage, aiming for all children to start school on an equal platform.

\section{Inclusive Education}

Inclusive education is enshrined in UK legislation, stretching back to the Education Act of 1944 and more recently underpinned by the Human Rights Act 1998, Race Relations (Amendment) Act 2000, the United Nations Convention on the Rights of the Child 1989 and the Equality Act 2010. Nonetheless, there is a tension between current education policy's measurement driven approach where schools are less likely to encourage underachieving pupils (such as those from Gypsy, Roma and Traveller backgrounds) to attend their schools with the inclusion agendas which aims to improve individual outcomes and underachievement (Bhopal 2011; Ryder and Cemlyn 2016). 
Inclusion is a complex concept with fundamental values of equality, rights and participation, but these are often also the very things underpinning exclusion. Therefore, to understand inclusion, it is necessary to first consider its opposite exclusion and the tension between them, as exclusion can create barriers to inclusion (Booth and Ainscow 2011; Borkett 2019; O'Connor and Bolshaw 2018). It is not enough to be 'included' by just being within the same environment, inclusion is about belonging, empowerment and participation (Borkett 2019). Hence, providing inclusive education involves: acknowledging children's rights to high quality educational experiences in a nurturing and supportive environment; reducing exclusion, discrimination and barriers to learning; and participation by fostering mutually sustaining relationships between schools and surrounding communities (Centre for Inclusive Education 2018). Traveller education support services (TESS) have been fundamental to the development of these principles and the promotion of inclusive education for Gypsy, Roma and Traveller children.

Traveller education support services were first introduced to the UK educational system following the influential Plowden report in 1967 which recommended child centred education and highlighted priority areas for improvement which included recognition of the need to improve outcomes for Gypsy and Traveller children stating that:

the needs of gypsy children cannot be effectively met by measures of the kind we recommend for the more general problems of urban deprivation. They will require special attention and carefully planned action. (Plowden 1967, p. 595).

Acting as 'cultural mediators' (Derrington and Kendall 2004), TESS provide a bridge between GRT families and schools promoting the development of trust between families and schools to ensure that GRT children obtain their full entitlement to education (Clark and Greenfields 2006). TESS provide a range of services including support and advocacy for GRT families, improving attendance and reducing exclusions, classroom support, information and training for schools, transitional support to secondary schools, providing outreach educational programmes and (Wilkin et al. 2009). TESS provision has been integral to the development of inclusive practice for GRT children. However, since 2010 austerity funding cuts have severely reduced education budgets resulting in a significant reduction or complete loss of the TES in some local authorities. The reduction of TESS challenges inclusive practice and risks marginalising GRT families further as their advocates and support services are diminished, the challenge for schools is to find alternative ways of supporting children using mainstream rather than specialist support services (OFSTED 2014). 


\section{Roma Integration Framework}

The Framework for National Roma Integration Strategies (FNRIS) was established by the European Commission in 2011 as a European wide inclusion strategy following the recognition of the multiple disadvantages Roma communities experience across the key social determinants of employment, education, health and accommodation. The aim was to improve social mobility and promote inclusion into mainstream populations. This required all EU states to develop national integration strategies focusing on the four social determinants mentioned above. In relation to education, the aims of the strategy were to: improve the access to and the quality of early childhood education; reduce segregation; and ensure that all Roma children complete at least primary school education. The UK's response was to suggest that existing legislation and wider social inclusion policies with some specialist interventions were sufficient. However, these mainly focus on Gypsies and Travellers, only referring to Roma in the context of education. Furthermore, there has been some criticism of this approach by civil society organisations who suggest that the UK is 'migrant blind' (Brown et al. 2014), arguing for specific funding support for Roma communities and fearing that current EU funding that supports many of the current interventions will be lost following Brexit (Ryder and Cemlyn 2016; Women and Equalities Committee 2019).

\section{The Arrival of European Roma}

As the largest ethnic minority group in Europe, estimated at between 10 to 12 million, Roma people have historically, and continue today, to experience widespread social and economic exclusion in their home countries (Bancroft 2005; European Commission 2011; James 2017; Morris 2016). Therefore, it is not surprising that many Roma families have taken advantage of the opportunities to improve their life chances. The numbers of Roma settling in the UK are unclear, as the 2011 National Census did not provide a separate category to identify as Roma. A more recent mapping exercise in the format of an administrative survey completed by the University of Salford estimates the Roma population at approximately 197,705 (Brown et al. 2014). However, the challenges with population counts of marginalised groups are that many will hide their true ascription because of longterm prejudice and discrimination, resulting in a significant underestimation of population numbers (Clark and Greenfields 2006; Ryder et al. 2014). Furthermore, the invisibility or perceived small numbers has a negative impact within policy and funding mechanisms as the needs of these communities are largely ignored (Brown et al. 2014). Similar difficulties are found with trying to identify the numbers of Roma children within schools. The 2018 school pupil Census for England estimates Gypsy/Roma pupil numbers of 39,672 across both primary and secondary school provision, recognising that this is probably underestimated as not all GRT families 
will identify their true ascription. Smaller numbers of 1320 pupils are recorded for Scotland, under ascription Gypsy/Traveller as Roma is not separately recognised (Department of Education 2018).

Although living in the UK offers more opportunities than their home countries, as a result of lower levels of discrimination and better employment prospects (albeit often unskilled work) (Brown et al. 2013), Roma families continue to face significant challenges. As a result of discrimination within their home countries educational outcomes can be limited, low literacy and skill levels mean that employment available to Roma is often within the unregulated economy, and below the minimum wage. Low income and access to employment also has an impact on housing. Contrary to the stereotype of a nomadic lifestyle, preferred by Gypsies and Travellers, Roma have lived in settled communities for centuries, living in extended and intergenerational family communities (Ryder et al. 2014; James 2017). Across the UK migrant Roma families have settled mainly in the north of England, Kent and London, with smaller communities in Scotland, Wales and Northern Ireland (Morris 2016). However, a lack of social housing means that these families often live in deprived urban areas with poor housing and often at risk of exploitation from private landlords (Ryder and Cemlyn 2016). Poor housing can lead to poor health, with difficulties accessing healthcare often due to language difficulties and their unfamiliarity with NHS systems. Therefore, Roma families alongside Gypsy and Traveller populations experience multiple disadvantages including high levels of poverty and poor health (Lane et al. 2014; Morris 2016; Cromarty 2018). Moreover, these outcomes perpetuate intergenerational cycles of disadvantage, with poor educational outcomes limiting employment, housing and health outcomes, all of which influence the developmental and educational outcomes of the next generation. Accordingly, education is central to improving social inclusion and fundamental to the rationale for many Roma families moving to the UK as the example below illustrates.

My daughter is at school from five... I want that she will receive a good education here and then she will have a job (Lane et al. 2014, p. 31).

In their home countries Roma children face significant barriers to education. Despite the right to education free from discrimination determined by the Human Rights Act 1998, across Europe the educational achievement of Roma children is amongst the lowest of all ethnic minority groups. Most notably in central and eastern Europe where entrenched education practice excludes or segregates Roma children (Council of Europe 2017). This starts early with most Roma children having little or no experience of early years education. This is in part due to limited early years provision and the structure of formal education starting at the age of six or seven. However, Roma children can face discrimination in accessing early years provision for number of reasons, including limited or no provision within the locality; institutional discrimination through non-allocation of places; and prohibiting transport costs (Greason 2016). Discrimination continues into formal schooling with Roma children placed in 'special' schools, segregated classes or in Roma only schools. Segregation in mainstream education is most prevalent in the Czech Republic, Hungary, Slovakia and Greece (FRA 2014). Although there are no official policies 
for segregating Roma children the chances of them being enrolled in a special school have been 27 times higher than for non-Roma children (Lane et al. 2014; Council of Europe 2017).

Placing Roma children in special schools or segregated classes has been heavily criticised and is in fact in breach of the European Roma Integration strategy (European Commission 2011). To avoid this criticism, these schools were renamed as 'practical' schools (ERTF 2015). However, changing a name does not change the provision and Roma children continue to be disadvantaged. Once in the 'special' or 'practical' school system children are taught a substantially reduced curriculum, as a result re-joining mainstream education or continuing to secondary school and fulfilling their potential becomes almost impossible.

\section{Roma Education in the UK, Inclusive Or Exclusive?}

As many Roma children will have experienced segregation or have little, or no formal schooling in their home countries, the inclusive approach to education in the UK should immediately improve their educational opportunities. Nonetheless, Roma children entering the UK education system face multiple challenges, not least because the educational systems across Europe differ from that of the UK. Hence Roma parents are unlikely to be aware of their statutory responsibilities regarding schooling, this can be further exacerbated by having English as an additional language. Moreover, the impact of poor parental education experiences and fear of prejudice and discrimination can create protective attitudes and a hesitance towards engaging with education authorities and schools (Greason 2016; Lane et al. 2014). In addition, cultural heritage and traditional views of education also create barriers, secondary school (11-16 years) curriculum and formal qualifications are perceived as less relevant than family-based learning and selfemployment, and the expectation of early financial independence, marriage and parenthood are often valued over formal education. Protective factors including concerns about community values being undermined by formal (e.g. sex education) and informal (drug culture) aspects of education are also prominent. There are also factors linked to the school educational environment that can lead to early withdrawal from school such as, early exposure to racism and bullying; social and cultural isolation; conflict with teachers or peers, a perceived lack of support in accessing the curriculum; and low teacher expectations in relation to attendance and achievement (Traveller Movement 2019).

Furthermore, social exclusion and disadvantage also translate to multiple barriers for educational inclusion in the following ways:

Bullying and exclusion-Roma children often experience ethnicity-based bullying and exclusion, often only socialising with Roma peers rather than other pupil groups. This can also lead to parents withdrawing children from school to protect them from prejudice and discrimination. 
Poverty and social disadvantage_parental socio-economic status and educational outcomes can hinder their children's social inclusion and social mobility. Poor and overcrowded living environments can impact on children's development and learning outcomes.

Low expectations of educational achievement-teachers will often have low expectations of Roma children's achievement, expecting early withdrawal from school. Inequality in health and wellbeing-poor health and wellbeing has detrimental impacts on children's development and subsequent educational outcomes.

Underdevelopment of home learning environments-parental support can be as difficult due to low literacy levels and English as an additional language.

Although UK education policy promotes an inclusive approach, in many cases this still does not always translate into good educational experiences for Roma children as social exclusion often follows them into the classroom. Whilst there is some evidence of improving outcomes, Roma children remain the lowest achieving and most excluded children of all ethnic groups within schools, with Gypsy/Roma pupils well over 2 years behind their peers (Hutchinson et al. 2018). Educational attainment remains disproportionally low with attainment at the end of secondary education (key stage 4) just $11.8 \%$ in comparison to 67.6 girls and 60.3 boys of white British children. Similarly, exclusion rates are highest for Gypsy/Roma boys (120.4 per 1000) followed by Gypsy/Roma girls (54.8 per 1000) in comparison to 24.2 per 1000 for White British pupils. Low attendance and achievement in statutory education also means that Gypsy, Roma and Traveller children are also under-represented in further and higher education (Andrew et al. 2017; Equality and Human Rights Commission 2018). Where separate data is available Roma children have marginally better educational outcomes than Gypsy and Traveller children, with $63 \%$ of Roma pupils with English as an additional language (EAL) remaining in school until statutory leaving age compared to $38.3 \%$ of Gypsies and Travellers, illustrating improving outcomes particularly for Roma children. Whilst there are undoubtedly still significant challenges in overcoming entrenched social exclusion and discrimination there is also evidence of inclusive and successful educational experiences for Roma children.

The current measurement and outcome focused education policy creates a tension with inclusion policies. The reduction of TESS has resulted in good practice in GRT education becoming exceptional rather than the norm. For school's the outcome focussed academic policy agenda creates a tension with inclusive practice as it is challenging to be able to achieve both. Some schools do not have sufficient understanding of GRT cultural heritage or provide sufficient support under the Equality Act 2010 to prevent discrimination and bullying (Traveller Movement 2019). Under these circumstances the poor outcomes experienced by Gypsy, Roma and Travellers are symptomatic of the failure of inclusion strategies, and the marginalisation they often experience. Conversely schools that have an inclusive ethos provide some excellent educational experiences and outcomes for children. These can be attributed to schools that promote a community focused approach working in partnership with families, pupils and local communities to develop an ethos of respect. They provide 
a flexible approach to learning and have high expectations of their pupils (Traveller Movement 2019).

\section{Examples of Good Practice Are Illustrated in the Following Case Studies The Roma Early Childhood Education Programme (RECEP)}

This early intervention project is delivered in partnership with the Altmore Children's Centre in London and offers weekly 'Stay and Play' sessions for children under five and their parents. There is also a parent support programme, which encourages parents to discuss their childhood experiences as part of learning more about their own children's development and how to confidently support their children's early learning within the UK education context. The development of trust and early engagement with parents enables a smoother transition primary school (Greason 2016).

\section{Parkside Community Primary School, Kent}

Is a small primary school in an area of high deprivation. The proportion of Roma pupils on roll was $10.3 \%$ in 2013 . The key ingredients of the school's success are strong commitment from the headteacher and governing body, a welcoming ethos and consistently effective communication with parents. This is achieved through good community links and an outreach worker with communications designed to be accessible, the school newsletter is pictorial, and parents receive texts rather than formal letters. Information is sent more than once to ensure that they do not forget events. The outreach worker makes home visits and feeds back information to the school. The curriculum is genuinely adapted to reflect the community's language, culture and values; this is not tokenistic. For example, a topic on homes included caravans alongside dwellings. The school reflects the tradition of oral story-telling but also places a strong emphasis on teaching reading. The impact of this support and commitment is reflected in outcomes for these pupils. In 2013, the attainment of Gypsy/Roma pupils at Key Stage 2 was well above that of Gypsy/Roma pupils nationally in reading, writing and mathematics and in line with that for all pupils in the school and nationally. Most importantly and reflective of the inclusive approach of the school, Parents report that the school respects their culture yet does not treat their children as 'different'. Roma pupils say they feel welcomed and valued (OFSTED 2014).

\section{Babington Community College, Leicester}

Is comprehensive school on the outskirts of Leicester, with a growing cohort of Roma students. In 2013, $10.7 \%$ of its pupils were identified as Roma or Gypsy compared with $3.9 \%$ in 2011 . The emphasis of the school is on high quality teaching not interventions.

Staff members had built up good relationships with Roma families, developing families' trust was vital in securing their engagement. The home-schoollinks worker and a Roma support worker run coffee mornings to build up relationships with the Roma community. 
Leaders spend time listening to parents and regular meetings ensure that the families are clear about and support Babington's expectations. Roma students' progress is outstanding from their exceptionally low starting points when they join the school, but their attainment is low compared with the national average for all pupils. However, some Roma pupils are in top sets, especially in mathematics. The curriculum has been modified to reflect Roma history and culture. The college celebrates gypsy/Roma Traveller month and involves families in musical events. Students arriving who are new to English are paired, wherever possible, with a student who speaks the same Roma language and dialect.

Key Stage 4 completion rates are very high for Roma pupils and the college tracks post-16 leavers closely, most of whom go on to Leicester College (OF STED 2014).

\section{Conclusion}

The prevailing neo-liberal approach to educational policy in the UK aims to improve outcomes for children, particularly those from disadvantaged backgrounds. Using a human capital approach that invests in early intervention to mediate early childhood disadvantage, this approach seeks to improve social mobility and reduce social welfare expenditure on adults disadvantaged as children. The resultant quasimarketisation and attainment focus of current education policy is at odds with principles of inclusion, not least because austerity funding cuts have had the greatest impact on support for children from disadvantaged backgrounds. Consequently, there remains a serious gap between policy and action for GTR communities as antigypsyism remains commonplace and the attainment gap wide with the lowest educational outcomes for GRT children.

The Roma community remain one of the most disadvantaged ethnic groups experiencing social exclusion and discrimination, which often transfers to the classroom with some Roma children continuing to experience persistent inequalities in educational attainment and over-representation among children excluded from school. The educational challenges and tensions for Roma children are numerous and often influenced by their cultural heritage where formal qualifications are perceived as less relevant than family-based learning, self-employment, and the expectation of early financial independence, marriage and parenthood. Early withdrawal from school can also be linked to the school environment with experiences of early exposure to racism and bullying; social and cultural isolation; conflict with teachers or peers, a perceived lack of support in accessing the curriculum; and low teacher expectations in relation to attendance and achievement. Nonetheless, whilst evidence suggests that there are many barriers within education, there are also examples of good practice as illustrated in the case studies. 
Inclusive education is achieved through the development of policies and legislative provision that includes excusing unauthorised school absence of children from families with an itinerant occupation, allocating extra resources and grants, to schools working with Roma pupils and building successful relationships between schools, families and the community. Demonstrating the synergy between inclusive practice within schools, wider community and social inclusion. Although there are examples of both inclusion and exclusion for Roma children in the UK undoubtedly, they have more inclusive educational experiences than in their home countries.

\section{References}

Allen, G. (2011). Early intervention. The next steps. London: Cabinet Office Publication.

Andrew, J., Robinson, D., \& Hutchinson, J. (2017). Closing the gap-Trends in educational attainment in education. Retrieved from www.epi.org.uk

Bancroft, A. (2005). Roma and gypsy-Travellers in Europe: Modernity, race, space and exclusion. Aldershot: Ashgate.

Booth, T., Ainscow, M. (2011). Index for inclusion, developing learning and participation in schools. Retrieved from www.csie.org.uk/inclusion/index

Bhopal, K. (2011). 'This is a school, it's not a site': Teachers' attitudes towards gypsy and Traveller pupils in schools in England, UK. British Educational Research Journal, 37(3), 465-483.

Borkett, P. (2019). Inclusion and participation. In D. Fitzgerald \& H. Maconochie (Eds.), Early childhood studies (pp. 149-165). London: Sage.

Brown, P., Martin, P., \& Scullion, L. C. (2013). Migrant Roma in the United Kingdom. Population size and the experiences of local authorities and their partners. Retrieved from www.salford. ac.uk

Brown, P., Martin, P., \& Scullion, L. C. (2014). Migrant Roma in the United Kingdom and the need to estimate population size. Retrieved from http://usir.salford.ac.uk/34914/

Centre for Inclusive Education. (2018). About inclusion. Retrieved from www.csie.org.uk/inclu sion/index

Clark, C., \& Greenfields, M. (2006). Here to stay: The gypsies and Travellers of Britain. Hatfield: University of Hertfordshire Press.

Council of Europe. (2012). Descriptive glossary of terms relating to Roma issues. Retrieved from www.coe.int/en/web/portal/roma

Council of Europe. (2017). Fighting school segregation in Europe through inclusive education. Retrieved from www.coe.int

Cromarty, H. (2018). Gypsies and Travellers. Briefing paper. Retrieved from www.parliament.uk

Davidson, N. (2013). The neoliberal era in Britain: Historical developments and current perspectives. International Socialism, 139. Retrieved from www.isj.org.uk

Department of Education. (2013). The primary national curriculum. Retrieved from www.gov.uk/ dfe/nationalcurriculum

Department of Education. (2018). School pupils and their characteristics, national tables. Retrieved from https://www.gov.uk/government/statistics/schools-pupils-and-theircharacteristic

Derrington, C., \& Kendall, S. (2004). Gypsy Traveller students in secondary schools: Culture, identity and achievement. Stoke on Trent: Trentham Books.

Diacon, D., Kritman, H., Vine, J., \& Yafal, S. (2007). Out in the open. Providing accommodation, promoting understanding and recognising the rights of gypsies and Travellers. British: Social Housing Foundation (BSHF). 
Equality and Human Rights Commission. (2018). Is Britain fairer? The state of equality and human rights. Equality and Human Rights Commission.

European Commission. (2011). An EU Framework for national Roma integration strategies up to 2020. Retrieved from www.eur-lex.europa.eu.

European Roma and Traveller Forum (ERTF). (2015). The situation of Roma in the Czech Republic. Council of Europe.

European Union Agency for Fundamental Rights (FRA). (2014). Education: The situation of Roma in 11 EU Member States Roma survey -Data in focus. Retrieved from www.fra.europa.eu

Field, F. (2010). Families in the foundation years: Preventing poor children becoming poor adults. The report of the independent review on poverty and life chances. London: Department of Education.

Gibb, N. (2015). Speech: The Purpose of Education. Retrieved from https://www.gov.uk/govern ment/speeches/the-purpose-of-education

Greason, L. (2016). Education a Roma perspective. Roma Support Group. Retrieved from https:// drive.google.com/file/d/0B2lw1_Krq5gnVm9BTEZXRmlveUk/view

Human Rights Act. (1998). Retrieved from www.legislation.gov.uk

Hutchinson, J., Robinson, D., Carr, D., Hunt, E., Crenna-Jenkins, W., \& Akhal, A. (2018). Education in England, annual report. London: Education Policy Institute.

H.M Government Equality Act (2010). Retrieved from https://www.gov.uk/government/speeches/ the-purpose-of-education

James, Z. (2017). Roma inclusion post Brexit: A challenge to existing rhetoric. Retrieved from www.pearl.plymouth.ac.uk

Lane, P., Spencer, S., \& Jones, A. (2014). Gypsy, Traveller and Roma: Experts by experience reviewing UK progress on the European union framework for national Roma integration strategies. London: Joseph Rowntree Foundation.

Marmot, M. (2010). Fair Society, healthy lives. Executive summary of strategic review of health inequalities. Retrieved from www.ucl.ac.uk

Marshall, J. (2018). Contemporary debates in education. Abingdon: Routledge.

McDowall-Clark, R. (2017). Exploring the contexts for learning, challenging the school readiness agenda. Abingdon: Routledge.

Mirga-Kruszelnicka, A. (2017). Revisiting the EU Roma framework: Assessing the European dimension for the post-2020 Future. Retrieved from www.opensocietyfoundations.org

Morris, M. (2016). Roma Communities \& Brexit: Integrating \& empowering Roma in the UK. London: Institute for Public Policy Research.

Moss, P. (2014). Transformative change and real utopias in early childhood education. Abingdon: Routledge.

Naydenova, V., Butler, I. (2014). A Roma reality check for the UK. Retrieved from www. opensocietyfoundations.org/voices/roma-reality-check

O'Connor, S., \& Bolshaw, P. (2018). Inclusive policy and practice. In S. Powell \& K. Smith (Eds.), An introduction to early childhood studies (pp. 187-197). London: Sage.

Office for Standards in Education (OFSTED). (2014). Overcoming barriers: ensuring that Roma children are fully engaged and achieving in education. Retrieved from www.ofsted.gov.uk/ resources/140195

Office of National Statistics (ONS) (2018). Population Estimates. Retrieved from www.ons.gov.uk/ peoplepopulationandcommunity/populationandmigration/populationestimae

Okely, J. (1983). The Traveller gypsies. Cambridge: Cambridge University Press.

Peckham, K. (2017). Developing school readiness, creating lifelong learners. London: Sage.

Plowden, B. (1967). Children and their primary schools: A report of the Central Advisory Council for Education (England). Retrieved from www.educationengland.org.uk

Ryder, A., \& Cemlyn, S. (2016). Monoculturalism, austerity and moral panics: Assessing government progress on addressing gypsy, Traveller and Roma exclusion. Journal of Poverty and Social Justice, 24(2), 143-155. 
Ryder, A., Cemlyn, S., \& Acton, T. (2014). Hearing the voices of gypsy, Roma and Traveller communities. Bristol: Policy Press.

Traveller Movement. (2019). A good practice guide for improving outcomes for Gypsy, Roma and Traveller children in education. Retrieved from https://www.travellermovement.org.uk

Wadsworth, J., Dhingra, S., Ottaviano, G., \& Reenen, J. (2016). Brexit and the impact of immigration on the UK. London: Centre for Economic Performance.

Warwick-Booth, L. (2019). Social inequality. London: Sage.

Migration Watch. (2018). The history of immigration to the UK. Retrieved from www. migrationwatchuk.org/briefing-paper/437

Wilkin, A., Derrington, C., \& Foster, B. (2009). Improving the outcomes for gypsy, Roma and Traveller pupils: Literature review. London: Department Children, Schools \& Families.

Women's and Equalities Committee. (2019). Tackling inequalities faced by Gypsy, Roma and Traveller communities. Retrieved from https://publications.parliament.uk/pa/cm201719/ cmselect/cmwomeq/360/360.pdf

Open Access This chapter is licensed under the terms of the Creative Commons Attribution 4.0 International License (http://creativecommons.org/licenses/by/4.0/), which permits use, sharing, adaptation, distribution and reproduction in any medium or format, as long as you give appropriate credit to the original author(s) and the source, provide a link to the Creative Commons licence and indicate if changes were made.

The images or other third party material in this chapter are included in the chapter's Creative Commons licence, unless indicated otherwise in a credit line to the material. If material is not included in the chapter's Creative Commons licence and your intended use is not permitted by statutory regulation or exceeds the permitted use, you will need to obtain permission directly from the copyright holder. 